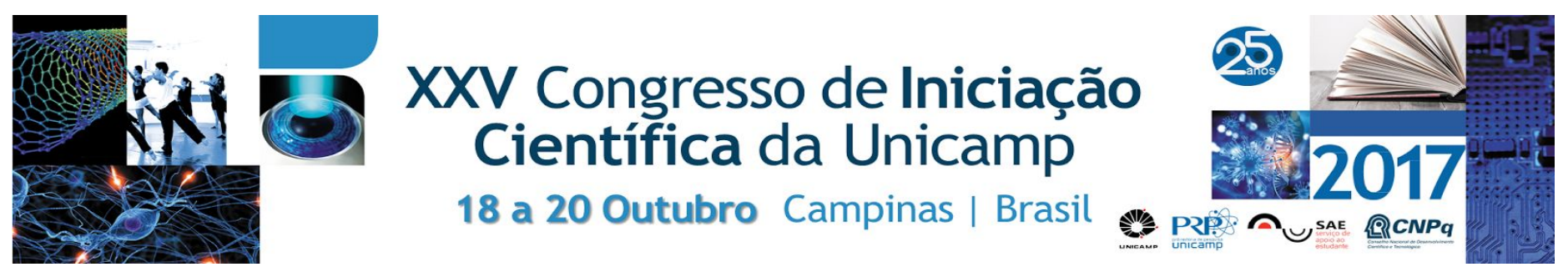

\title{
A Reação de Belousov-Zhabotinsky - Um breve histórico sobre sua descoberta e evolução
}

\section{Bianca Tieme Kitagaki, Maria Rodrigues Pinto, Raphael Nagao*}

\section{Resumo}

A descoberta da reação de Belousov-Zhabotinsky é considerada o marco inicial dos estudos sistemáticos das reações químicas oscilantes. Tais reações formam espontaneamente padrões auto-organizados quando mantidas afastadas do equilíbrio e são capazes de mimetizar diversos sistemas biológicos encontrados na natureza.

\section{Palavras-chave:}

reações oscilantes, reação de Belousov-Zhabotinsky, sistemas complexos

\section{Introdução}

Reações oscilantes são processos químicos irreversíveis cujo comportamento complexo é mantido apenas quando o sistema está afastado do equilíbrio termodinâmico "i. O sistema é dito complexo, pois os elementos que o compõem interagem sinergicamente a fim de gerar uma estrutura espacial em escala superior ao da unidade individual. A celebrada reação de Belousov-Zhabotinsky (BZ) é um exemplo clássico de uma reação química oscilante caracterizada por possuir uma etapa reacional autocatalítica associada à uma etapa inibidora. Essa reação é muito conhecida devido à mudança periódica de cores (e.g. vermelho e azul quando utilizado ferroína como catalisador) e à formação espontânea de padrões auto-organizados, como mostrados na Figura 1.
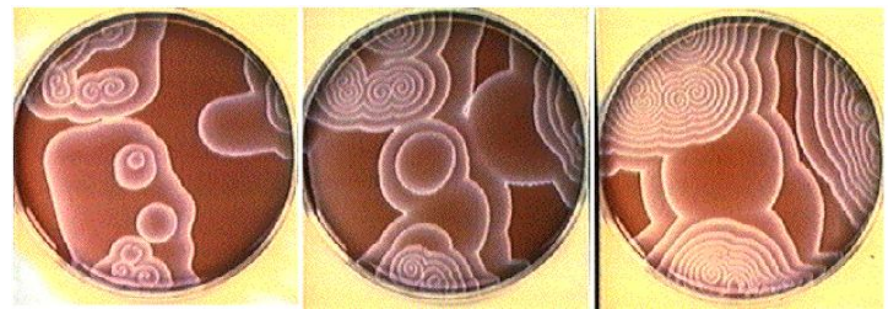

Figura 1. Padrões auto-organizados na forma de alvos e ondas viajantes na reação $B Z^{\prime \prime}$.

Neste trabalho discutiremos, sob um ponto de vista histórico, a descoberta e a evolução da reação BZ, abordando aspectos importantes como o mecanismo reacional e o modelo de Field, Körös e Noyes (FKN) que descreve com precisão a dinâmica do sistema.

\section{Resultados e Discussão}

A reação BZ teve seu início por volta de $1950 \mathrm{com}$ os experimentos de Belousov que visava modelar a catálise do ciclo de Krebs a partir da oxidação de um substrato orgânico ${ }^{[2}$. Inesperadamente, a reação alternava sua cor periodicamente o que indicava não apenas o consumo de reagentes e a formação de produtos, mas também o caso inverso, em que os produtos regeneravam os reagentes de forma consecutiva. A comunidade científica acreditava que $\mathrm{o}$ experimento feito por Belousov contrariava a segunda lei da termodinâmica que postula que a entropia de um sistema isolado deve aumentar até atingir um valor máximo no estado de equilíbrio. Belousov, portanto, encontrou uma grande dificuldade de publicar seus resultados experimentais. Poucos anos depois, Zhabotinsky deu continuidade ao trabalho de

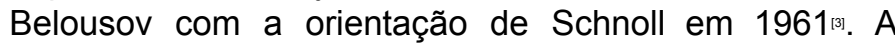
variação da concentração das espécies que compõe a reação oscilatória foi estudada sistematicamente além da definição de etapas químicas importantes como a autocatálise. Zhabotinsky ainda descobriu que se uma pequena alíquota da solução fosse alocada numa placa de Petri, padrões auto-organizados espaço-temporais surgiam espontaneamente. Mesmo depois dos estudos de Zhabotinsky, a reação só foi aceita pela comunidade científica após Field, Körös e Noyes definirem um mecanismo químico simplificado, e seu respectivo modelo denominado Oregonator, que engloba as principais etapas essenciais para o nascimento do comportamento oscilatório, não violando a segunda lei da termodinâmica". Desde então a reação tem sido utilizada para estudar a formação espontânea de padrões na natureza, tais como a propagação de pulsos elétricos no coração ou o processo de morfogênese em redes químicas acopladas.

\section{Conclusões}

Oscilações químicas são processos que surgem quando o sistema está afastado do equilíbrio. A reação de Belousov-Zhabotinsky é um dos primeiros sistemas desse tipo a ser estudado e entendido com profundidade. Dado o progresso, essa reação é amplamente utilizada como um sistema-modelo biomimético.

\section{Agradecimentos}

Agradecemos a orientação do Prof. Dr. Raphael Nagao pela orientação e auxílio na elaboração do estudo.

[1] Gray, C. R, Davis, J. M., An Analysis of the Belousov-Zhabotinkskii Reaction, The High School Summer Science Research Program, 2001,

[2]Winfree, A. T.; J. Chem. Educ. 1984, 61, 661.

[3]Faria, R. D.; Quim. Nova 1995, 18, 281

[4]Scott, S. K., Oscillations, Waves, and Chaos in Chemical Kinetics, 1994 